\title{
The Motivational Factors of Heritage Language Learning in Immigrant Bilingualism
}

\author{
Tuba Yilmaz
}

\begin{abstract}
Research shows that the heritage language which is used in immigrant homes as a symbol of ethnic and cultural heritage disappears in two to three generations in the USA. Different factors contribute to this disappearance. The purpose of this study is to identify the factors that cause immigrant children's rejection of their heritage language and switching totally to English for daily conversation when they start schooling with native English speakers. Besides, it aims to figure out the motivational factors that encourage them to (re)learn their heritage language after a period of time. To reveal these factors, the study will examine what these immigrant bilingual speakers' experienced while learning two languages, what kind of challenges they faced with, and how they made their linguistic choices. For this study, four participants from different ethnic backgrounds were recruited based on their heritage language learning processes, and interviewed. The interviews took 15-20 minutes with per participant. Results show that the practices of schools and parents can have a subtractive effect on immigrant children's bilingualism Identity, family interaction, bilingualism, social pressure and stereotypes can also have a motivational effect.
\end{abstract}

Index Terms-Bilingualism, heritage language learning, language shift, subtractive ideologies.

\section{INTRODUCTION}

Maintaining heritage language can be difficult for immigrants in the United States of America because of policy makers', teachers' and parents' subtractive ideologies and practices. Research shows that a heritage language which is used in immigrant homes as a symbol of ethnic and cultural heritage disappears in two to three generations in the US [1] [2]. The English - only movement, which insists on the use of only English when schooling immigrant children has accelerated this disappearance [3]-[5]. Research suggests that after starting school, children of immigrant families gradually start to increase their English use, and decrease the use of home language in their lives in order to be accepted by the target community and to socialize. Besides, they think they need to shift to English in order to be successful at school [6]. As a result, their first language is replaced with English gradually [7], and their communicative competence in their first language, which helps them maintain interactions with people from the same ethnic background [8] fades away. The situation can be very destructive for these children because they learn English at the cost of their heritage language. Parents who realize the negative effect of the English-only movement on their children's bilingualism

Manuscript received September 9, 2014; revised November 12, 2014

T. Yilmaz is at the University of Florida, Gainesville, FL 32610 USA (e-mail: tubaylmz@ufl.edu). have looked for a solution to the problem by sending their children to heritage language schools at the preschool level [9]. Although heritage language schools have helped the children preserve their heritage language to a certain point [7], the language loss or language shift still exists at a high level among immigrant children in the US.

As a researcher who is interested in language loss, language maintenance and language revitalization among immigrant people, I talk about the language loss with different immigrant college level students studying at my college. I have realized that the students who experienced language shift (replacement of their first language with English) when they were children, made an attempt to relearn their heritage language after a period of time. While some of them failed in re-learning their heritage language, some of them really succeeded. In this study, I will explore the subtractive factors that caused their language loss at the first place, and the additive factors that motivated them to relearn their heritage language.

The purpose of this study is to reveal the experiences of immigrant children at different schools. These children whose parents and teachers have different ideologies will reflect their experiences from their own viewpoint in this study. The study is different from previous studies because I interviewed the children (who are now grown-ups) instead of their parents. Although they cannot remember every detail of their rejection of their first language and the relearning process, they remember how they felt, the factors that cause them reject their first language during childhood and the factors that motivated them to relearn their heritage language later in life. The study can have a broad impact on policy makers and teachers since it provides long-term results of English-only schools and bilingual schools in terms of heritage language maintenance, and since it explains the situation from the viewpoint of students. However, since the sample of the study is very small, the results may not be generalized to whole immigrant population graduated from English-only or bilingual schools.

\section{LITERATURE REVIEW}

First language acquisition occurs effortlessly and successfully for most children [10]. Children acquire their first language to engage in conversations, to interact with people, to discover the world around them and to function in that world appropriately [8]-[13]. They listen to the language spoken around them very carefully and patiently, try to make sense of words and sentences, and make associations with these words and certain nonlinguistic events during the 
language acquisition process [11]-[14]. In the end, based on their observations and participation, they become capable of communicating with their parents in their home language.

\section{A. What Is the Role of Schools and Teachers in Language Loss?}

When immigrant children start to school, they have to discover a new environment different from their home, and engage in this new environment actively. Although the discovery and involvement alone are difficult enough for the children, when this new environment's language is also different, it becomes even much harder for them because then the burden on their shoulders doubles. That can be one of the reasons why many immigrant children who are actually very skillful in communicating with their first language stay silent at school [15]. In order to take an active role in the classrooms, these students must perceive and understand the meaning of speech spoken at school [16], but this can be very difficult for the immigrant students who probably meet the language for the first time at school.

At school, the children whose first language is different from school language have to learn not only the content but also the language related to content to create new lexical bundles in their brains and relate them with their existing bundles in their first language [17], [18]. Teachers have a big responsibility to make the bundle formation process easy. If teachers involve these students' first language and culture into the classroom discussions, give voice to their inner egocentric speech and use this information as a resource, then the learning becomes more permanent, easy and fun for these children [11], [19], [20]. For example, Xiaodi, a Chinese boy who came to the US at the second grade, developed his second language speaking ability and literacy quickly through his nurtured relationships with his classmates and teacher [21]. Besides, in this case, the teachers' attitude will show the students that their home languages are actually respected, valued and used as a resource in the target community [7]-[9]. Teachers should also have a good understanding of second language development of these students, and accommodate their instruction accordingly to be encouraging. However, research suggests that the real case is usually just the opposite. [22] found in their study with 79 teachers that a big number of teachers undervalue immigrant children's first language, and they actually believe that maintaining first language places a big barrier in acquiring the second language, English. However, this is not the real case. [23] found that first language actually establish a foundation for second language development. Unfortunately, these subtractive practices and beliefs of teachers can make a big negative impact on children's linguistic choices and result in first language loss [24]. Teachers' ideologies are also absorbed by English speaking students, and these students start to behave in the way their teachers do towards their immigrant peers. In the classrooms where the teacher thinks the heritage languages are "inferior, useless and even subversive" [24], the native English speaking students would make fun of their immigrant friends and tease their culture. They behave in this way because immigrant students are 'outsiders' for them as they are different [8]-[25]. Reference [2] revealed in their study with Hispanic and American students at a middle school in California that students from minority culture backgrounds are discriminated against by native English speaking students, and seen as low status students. Although a big majority of the school came from Hispanic heritage background, the dominant population's values marginalize the minority culture in this case. In that school, students' status was determined by their English speaking ability. That's why many immigrant students reported in the study that they were ashamed of their first language and culture, and they wanted to learn English as quickly as possible to be an 'insider' in the community, even if it will cost them their first language [7], [8]. These subtractive attitudes of English speaking students prove that not many immigrant students are as lucky as Walter (an immigrant polish kindergarten child) who is not only welcomed but also helped to be a part of the community with his differences by his friends [26].

\section{B. What Is the Role of Parents' in Language Shift of their Children?}

Parents' attitudes towards the heritage language play a big role in their children's linguistic decisions [7], [27]-[28]. Research shows that there is a positive correlation between parents' positive attitudes towards heritage language and the children's success rate in maintaining it. Like the children in Trackton, Roadvile and Maintown communities [13], the children of immigrant families learn not only their heritage language but also the discourse and socio-pragmatic rules in their home communities, and they are very good at maintaining communication with their parents. The situation in the USA often continues until the children start school in an English-only environment. When these children start school, their performance can be low because of their linguistic limitations. Parents who want their children to succeed at school usually consult the teachers about what to do at home to increase their children's academic success. Unfortunately, many teachers, like Charles' teacher in [29], often recommend parents not to speak the heritage language at home, but English to speed up their acquisition of English. The immigrant parents, who have experienced discrimination, and had hard time finding a job in their US journey because of their outsider identity, follow these suggestions desperately, and allow their children to use only English at home to promote their English proficiency even if their communication becomes limited because they are not proficient enough to communicate well in English [7]. However, there are also immigrant parents who insist on their children's bilingualism, and encourage children to use both languages at home [30]. The children of these parents can maintain both languages and become bilingual. As a result, parents' practices can have both subtractive and additive role on their children's heritage language maintenance.

\section{What Happens after the Language Shift of Immigrant Children?}

The immigrant children who have difficulty in maintaining communication with their peers because of cultural differences and linguistic limitations [31] usually start to use English rather than their heritage language in their daily 
communications at home. They can begin to devalue their heritage language since it becomes a barrier for interaction with their peers and teachers at school, and focus on learning the rules of conversational structures to function appropriately in different spheres [16], which is one of two types of knowledge needed to engage in successful dialogues with their peers [31]. The other requirement to maintain a dialogue successfully is to have a big amount of content knowledge for conversational relevance. They can prefer to use English not only at school but also at home with their parents even if their parents do not know English at all [32]. As a result of children's language shift, a gap can occur between parents and their children [33]. Parents cannot convey their messages in the child's most dominant language due to their own low proficiency level in English. Besides, they may not transfer their heritage values, beliefs, culture or wisdom to their children. Children who start to forget their heritage language tend to devalue their heritage culture, and become assimilated quickly [7]. Thus, the languages that parents and children use to communicate begin to differ, and children gradually lose their cognitive ability necessary to recognize and understand the beliefs and desires of their heritage culture [33], [34].

\section{How Can Immigrant Parents Preserve Their Children's Heritage Language?}

One way to preserve heritage language is to make it useful and purposeful for the children because they learn their first language at the very beginning for a purpose which is communication with parents [10]. So that children can use their first language as a tool to reach knowledge before they use English for the same purpose, some parents send their children to heritage language schools at the preschool level [7]-[25]. By this way, children will initially use the representational function [12] of their first language before they use English for the same function when they start their regular English-only schooling. Some other parents send their children to bilingual schools to make them learn English gradually, and not forget their heritage language [7]-[35]. "The no-cost study on families" study of [36] shows that $74.6 \%$ of children who have taken preschool education in their heritage languages can maintain their heritage language even after schooling in English-only mainstream classes. On the other hand, whereas $30.6 \%$ of the children who had preschool education in English only or bilingual schools preferred to use only English in their daily communication, 46. $7 \%$ of them were able to use both languages [7]. Although this study does not provide information about the English proficiency levels and English use of the first group, the result $(74.6 \%)$ is quite impressive, and suggests that heritage language schools might actually help immigrant children to preserve their heritage languages for the long term.

\section{E. Why do Parents Send their Children to Heritage Bilingual Schools?}

Parents choose heritage bilingual schools instead of English only schools for their children's elementary school education for three main reasons: Cultural heritage, family relations and cognitive benefits of bilingualism [7], [29]-[32]. Immigrant parents believe that maintaining the language is the key to preserve their heritage culture and identity. In the study of [28] Hispanic parents stated that they viewed Spanish "as a marker of ethnic identity", and it should be preserved in order to preserve heritage cultures, values and family unity [37]. Parents teach cultural values and beliefs to their children through the communication in the heritage languages. Since losing their heritage language often means losing identity, parents send their children to heritage bilingual schools rather than English-only schools.

Heritage languages also play a critical role in maintaining family relations and building a heritage community. [38] notes that when the heritage language is lost, the family ties get weaken, and family unity is destroyed. In order to keep communicating their relatives especially living in the home country and speaking only the heritage language, immigrant children should maintain their heritage languages. In [38], Korean parents wanted their children to maintain the heritage language so that they could keep communicating with their grandparents living in Korea. Thus, heritage bilingual schools are usually more attractive for immigrant parents than regular English-only schools.

Lastly, although the main focus is maintaining the heritage language and making children literate initially in heritage language, heritage bilingual schools also prepares students for the English dominant society by teaching them English gradually. These bilingual students who know both English and the heritage language have more cognitively developed brains compared to monolinguals. Research suggests that bilingual children outperform monolinguals on pragmatics, metalinguistic abilities, and controlling attention [39]. Moreover, [39] found in their study that bilinguals have more enhanced cognitive ability and mental flexibility. Based on research results, we can conclude that with correct testing methods, bilingual students can perform as good as or even better than monolinguals on the academic performance tests. As a result, the outcome that encourage bilingualism and biliteracy often makes the heritage bilingual schools more appealing to parents compared to English monolingualism of English-only school.

\section{PARTICIPANTS}

For this study, four participants from different ethnic backgrounds were recruited based on their heritage language learning processes, and interviewed. The participants were informed about the study through announcements during social activities and e-mails, and the people who expressed to participate voluntarily are recruited. Two of the participants were from Turkish background, one participant was from Greek background and the last participant was from Hispanic background. The participants were all born in the USA, and they were second or third generation immigrants. They were all over 18 years old, college students (undergraduate or graduate) and females. Three of the participants' first languages were also their heritage languages. They learned their heritage languages at home from their parents, but they started to reject it when they contacted with native English speakers at schools, and they forgot it gradually. However, they relearned them after a certain period of time (different in each person's story). The fourth participant had never learned 
her first language during childhood, but she learned it in college.

\section{METHOD}

The interviews took 15-20 minutes with per participant, and they were held at the places the participants preferred. The interviews were audio-recorded with the participants' consents so that I could transcribe and analyze them in detail. The interview questions were divided into three sections. The first section included questions about first language rejection, language shift and relearning. The second part included questions about the role of school in their rejection and relearning. The last part included questions about role of parents. The questions were formed based on previous research findings, and research questions of this study.

\section{RESUlTS AND DISCUSSION}

Four participants were interviewed for this study. The first participant is Kelly who is 19 years old and has Turkish ethnicity. Her mother is from Turkey and her father is from Ireland. Her parents moved to the USA 19 years ago. She was born in Florida, and she is a fluent English and Turkish speaker. She learned Turkish at home as a first language, but she rejected it when she started kindergarten and forgot it gradually. She started to relearn it when she was at high school through her own resources such as internet, soap operas, books and online conversations with her relatives in Turkey.

Ally is 19 years old and she has Greek ethnic background. Her mother and father are from Greece, and she is the third generation in her family in the US. She was born in Florida, and she is a fluent English and Greek speaker. Her first language is Greek. She rejected her heritage language at the age of 2-3 when she started her preschool education in an English-only preschool program. Her relearning occurred when she started the first grade because her elementary school was a bilingual school with two-way immersion program.

Mary is 24 years old, and she has Hispanic ethnicity. Her mother is from Argentina and her father is from Uruguay. Her parents moved to the USA 30 years ago, and she is the second generation immigrant in her family. She was born in New York and she is a fluent English and Spanish speaker. Her first language was Spanish, but she rejected it at the age of 4 when she started her preschool education at an English-only preschool program. Her relearning occurred when she enrolled Spanish course at high school.

Lastly, Ellie is 25 years old, and she has Turkish ethnicity. Her both parents are from Turkey, and they have been living in the USA for 35 years. She is the second generation in her family, and she is fluent in English, and high-intermediate in Turkish. Her first language is English. Because her parents had negative experiences with her brother's academic life, they decided to teach her English as the first language. She learned Turkish through formal instruction and communication with Turkish people when she was in Turkey for a year through a study-abroad program in her college years.

In this part, I will discuss the interview results under two headings: the subtractive factors that caused language shift of immigrant children and the factors that motivated them to relearn their heritage language (see Fig. 1). Then, I will discuss the suggestions to teachers and parents made by participants based on their experiences.

\section{A. The Subtractive Factors That Result in Language Shift \\ 1) School}

School plays a very big role in immigrant children's language shift. Excluding immigrants' language and culture and viewing them as outsiders can be some example subtractive ideologies of schools. Other than Ally who studied in two-way immersion program at elementary grades, all the participants found the schools' ideologies very subtractive. Kelly states that:

...I was foreign, and no one knew Turkish, so I would go to school, and I remember I would call certain things like maybe water "su" like the language you know, the other word for it, and people would be like 'what are you speaking?'. They would make fun of me for being different, and being from Turkey, guble guble (laughs).

Her experiences show that immigrant children can be labeled outsiders and humiliated for speaking a language different than English. Similarly, Ally notes that her rejection of her heritage language and shifting to English was most probably because she wanted to fit with everyone else around her. In other words, she wanted to feel insider in the school community.

$\begin{array}{ll}\text { Subtractive Factors } & \text { Additive Factors } \\ \text { School } & \text { Identity } \\ \text { Parents } & \text { Family Interactions } \\ \text { Social Pressure } & \text { Bilingualism } \\ & \text { Social Pressure } \\ & \text { Stereotypes }\end{array}$

Fig. 1. Subtractive and additive factors for Heritage language maintenance.

Disregarding the other cultures or viewing them inferior can be another ideology observed at some English-only schools. Ally says:

"I don't really remember any of my teachers trying to talk to me about Greek, or you know being interested that I knew Greek. So it didn't seem as important. ... these younger children are very influenced by what their teachers think of them and everything, so if there was something nice at their speaking another language, then that could affect. That school definitely affected how I feel,"

Ally's statement supports the proposition that teachers' ideologies are absorbed by the children, and since her preschool teacher did not value to her heritage language, she rejected her first language. She explains her rejection like that: 
"When I was about 2, that's when I learn English, just from learning in school, and when I would come back from school, my mom would talk to me in Greek. I don't remember it, but she told me I would scream 'don't speak that language', and I didn't wanna speak Greek anymore."

Influenced by her teacher, she started to view her heritage language inferior. Mary makes a similar emphasis on the hegemony of English when I asked her the reasons for her forgetting her first language and shifting to English. She says that:

"I guess because English was relevant for school, and they put me in the ESL, so they made it seem like that was more important at the time, knowing English and interacting and doing everything in English."

Lastly, schools' limited resources for other languages can have a subtractive effect on immigrant children's language decisions. The immigrant children whose heritage language is not respected by dominant culture usually do not have a chance to use their heritage language as a resource in English-only schools. There are not elective language courses, or books or other materials in many languages. Even at high schools, the students were not allowed to choose their heritage language as a foreign language. Mary who took Spanish courses at high school to relearn her heritage language explains the story like that:

"When I was in high school, we were forced to take either Spanish or German. And we weren't supposed to take Spanish because we already had some background in it, but I kind of broke the rules, and signed up for it."

As a result, English-only preschools or elementary schools may have the highest subtractive role in language shift of immigrant children. Their ideologies, practices and limited resources may leave no choice but to lose their heritage languages to immigrant children.

\section{2) Parents}

Parents' ideologies have a big impact on children's linguistic decisions [30]. While some parents decide to teach their heritage language to their children, some parents choose to teach only English. Their decisions are mostly shaped by their experiences. Except from Ellie, all participants learned their heritage languages first, and English second. Ellie's parents decided to teach English to their daughter because of their negative experiences with their older child. Ellie explains the story in this way:

"Because my brother learned Turkish first, he is 5 years older than me, he actually spoke English later. He did poor at the beginning (at school) when he was learning English, so my parents were afraid and they didn't want my experience to be like that, so they just didn't teach me Turkish at all."

Thus, Ellie's parents wanted their daughter to be successful at school, and they see English the only way out. On the other hand, Ally's mother who also had negative experiences at school because of her limited English proficiency decided to teach her daughter Greek as a first language. Ally says:

"...she (her mom) remembers being five years old and going into kindergarten and not knowing what the teacher was saying, just crying all day, she had no idea what was being said, but she was raised with Greek as her first language, you know, felt that it should be same for me and for my brother."

As a result, parents' experiences have different impacts on their decisions with their children, but they definitely play a role in the decision making process about their children's schooling.

Parents' flexibility can be another subtractive factor that results in language shift. Parents are usually confused with which language they should speak with their children at home. They sometimes get suggestions from schools which are mostly subtractive, and they start speaking only English at home. However, when they did not know English very well, they speak only the heritage language, but allow their children to speak English at home. Mary tells that when she gradually decreased her use of Spanish and increased the use of English at home, she would speak English to her parents and they would respond her in Spanish. She adds that this pattern continues even today. In the same way, Kelly's parents did not force her to speak in Turkish when she started to reject her L1 at home. She explains the situation in that way:

"...she (her mom) never forced me to speak it. She wanted me to be comfortable, and she knew, like, we are at school here, we are grown up here, and of course as a parent, you want your children to be the best they can be at school, and in order to do that here, you have to be proficient in English. It is not just only being good at English, but you know it helps in so many subjects, so my mom was not adamant about me learning Turkish or speaking Turkish."

Like Kelly's mother, many immigrant parents are under the influence of school success issue, and they are usually flexible in their children's language choices because they want them to be successful at school.

Family relations can have a subtractive effect on immigrant children's linguistic decisions, too. Kelly's grandparents were very concerned about their granddaughters' English speaking ability that they warned her mother to teach English to their grandchildren. Kelly explains the story in this way:

"..when I was in kindergarten and first grade, I would visit my grandparents, eh, on my father's side who are American. They lived in Tennessee, and they would complain to my mom that I couldn't speak English very well with them, so they would say, 'oh well, I want to speak English with my granddaughters'. At the time, my dad knew Turkish, so it wasn't a problem for him speaking (Turkish) at home with us, and so I guess I think a lot of the incentive for me losing the language or rejecting it was because of my family, and school, of course."

Similarly, Ellie's family in the host country had also a subtractive influence on her learning Turkish. She says that:

"When I went to Turkey, I wouldn't have to learn (Turkish), I would totally survive, because my aunts, my uncles and my cousin, they would speak English with me. And 
they wanted to improve their English, they wouldn't try to push me to Turkish."

As a result, the ideologies of the members of the family can influence immigrant children's decision to maintain or learn their heritage languages.

\section{B. The Factors That Motivate Immigrant Children to (Re)Learn their Heritage Language}

Immigrant children, who experienced language shift when they started to school, often make attempts to relearn their heritage languages for different reasons at later ages. However, the time that they make their first attempt to relearn it may depend on one's experiences. In this part, I will discuss the factors that motivated the participants to relearn their heritage languages years later.

\section{1) Identity}

All the participants emphasized the relationship between their heritage language and their identity. They told that they wanted to relearn their heritage language because it was a part of their identity. When I asked Ally what her heritage language represented, she said:

"Now, it's part of my identity. I mean I know I was born here but my, you know that's a big part. I hope to carry it on eventually, you know. And not let it be forgotten because most of my family is still in Greece. So it is a big part of my life."

\section{Likewise, Ellie stated that:}

"So I think I was gravitating towards learning my language more formally, going abroad, and all about it because I wanted to kind of more about ... myself, I mean understanding my culture and, so I could develop that or my identity better."

\section{Mary also stated that:}

"I just felt like, I mean it is also part of my background. Also like losing, it's like a sense of identity. So if I lost that, I don't, you know. I would ideally, I would like to pass that on my children, too. That's also a reason why I keep it going."

As a result, all participants claimed that their heritage language was a part of their identity that should be learned and also transferred to the other generations.

\section{2) Family interaction}

Maintaining family interaction can be another significant factor that motivates the immigrant children to relearn their heritage language. Ally whose grandparents are in Greece explains why she wanted to learn Greek:

"I had actually gone to Greece when I was five, when I was still learning again. And my grandma, I remember her crying because I had forgotten all my Greek, and I didn't know how to speak with her. And my mom would have to speak with her for me. And I didn't like that. And I wanted to be able to speak to my grandma, and you know I only knew just words,.. so she had chickens, I only knew how to say chickens, eggs. I didn't know how to make a whole sentence to ask her to go to see chicken. So I wanted to learn again. I remember that because I wanted to speak again with my family very much."
Marry also states the influence of family interaction on her decision to relearn Spanish. She says that "when I go home, and my grandmother is there..., I have to speak Spanish. When I call anyone who doesn't, my family who doesn't live here, I have to speak Spanish.” Kelly's family in her host country was not only the reason but also the resource in her learning. She says she learned Turkish to interact with her cousins, and she developed her Turkish by chatting online with them in Turkish. Lastly, Ellie's grandmother helped her learn Turkish when she was taking Turkish classes in Turkey. She says that she would take her homework to her grandmother to check her mistakes, and correct them. Therefore, participants' need to interact with their family members in their host countries led them to learn their heritage language back.

Lastly, the participants state that their parents were very supportive with their (re)learning their heritage language. Ally states that "at home I would watch, my mom would buy Cinderella in Greek, or buy you know things like that". Ellie mentions that:

"They (her parents) always make me feel really good about my ability to speak, they are like 'oh you're speaking so much better this year, or you speak so much better than you say you do' you know. Even though I don't know that's true, they are very encouraging, so it's a point of connection for me and my family and connection to my heritage, so that's really nice."

Kelly shows her feelings about learning Turkish again with these words "It felt really good to be able to talk, like relearning finally for my family and for myself." It means her family supported her in her relearning process and they are pleased now that she can speak Turkish.

\section{3) Bilingualism}

The participants explained their reasons for being bilingual in different ways. Ally notes that she learned her heritage language because it was impressive to other people:

"I would probably say that it was cool when other people heard that I spoke another language, so with my other friends, it's "waww, you speak Greek", so that was kind of big plus to, to learn it again, and my family of course as well."

Kelly explains the contribution of her bilingualism to her life like that "What matters is when you, you know, maybe work your brain and explain yourself, it makes you unique, it makes you like learn better." Kelly adds that:

"Most people in the world know how to speak English, even my family, so being able to speak Turkish is more rare, and it is very convenient at times when you don't want someone to understand you."

As a result, the participants learned their heritage language because it is cool, because it helps their brain work well, and because it is an advantage and qualification that most people do not have, which all can be regarded as the advantages of bilingualism.

\section{4) Social pressure}

Social pressure plays not only a subtractive role, but also an additive role. Kelly states that there is a social pressure to 
know your heritage language if you are immigrant. She says that: “..When I was younger, I wouldn't know how to say it (the Turkish name of an object), and they (her peers) would be like 'why don't you know it if you are Turkish, you're not really Turkish'." Ellie felt the same social pressure when she was in college. She says that:

"A lot of unfortunate interactions, confrontations of people in my college kind of forced me to realize that I am not as connected to my identity and .. I need to either drop this identity which my brother did, he stopped, I mean he is Turkish, but he doesn't speak Turkish, he doesn't go to Turkey at all, or I need to really embrace it, so I can be more supportive, which what I tried to do by going abroad (Turkey)."

Mary also felt a social pressure from her heritage culture community, and it motivated her to speak Spanish. She says "When I call anyone who doesn't, my family who doesn't live here, I have to speak Spanish. I also make trips to other places, make friends who only speak Spanish, and I worked with people who only speak Spanish." As a result, social pressure can be both subtractive and additive (motivating) to immigrant children depending on the situation and society.

\section{5) Stereotypes}

Two Turkish participants were very concerned about stereotypes in American culture towards their culture. Ellie states that:

"What happened in college was I was exposed to a lot of people who, so post 9/11, people who were against Muslims which I'm identified with, but it was very complicated identity because not many, we had a Turkish community but not a religious community, so Muslim and Turkey is very westernized, so you know it is not a very traditional looking. "

Her utterance shows that she was disturbed by stereotypes of people, and she wanted to change it by learning more about her identity, and she started by joining Turkish community, and learning Turkish. Likewise, Kelly proposes that:

"They (American people) should, first of all, make sure, like, have a better understanding of there is a world beyond the America, and the languages beyond English. And by doing that, like, we tend to focus a lot, I know me growing up, I don't know if it's a regional thing because I grow up in Florida, even in college, like all of my professors, all of my teachers have always focusing outside of the US is South America."

Kelly's utterance shows that she is disturbed by people's limited knowledge and awareness about her culture. Therefore, one of the reasons that motivate her to learn her heritage culture and language is to inform people about it. Turkish participants felt frustrated about people's attitudes towards their culture, and they learned their language and culture to change the stereotypes by informing people about their culture.

\section{Suggestions to Parents, Teachers and Test Designers}

As people who experienced language shift because of the reasons mentioned above, I asked my participants what their suggestions are to teachers and parents, and they made significant suggestions that would be helpful for teachers and parents who are concerned about immigrant children's heritage language maintenance (see Fig. 2).

\section{1) To parents}

The first and most important suggestion to parents from all participants is that they should encourage their children to speak both languages at home. Kelly says that:

"I think that it is very important to maintain both. My mother did not stress that or force that, but that was because she did not realize, like, how important it could be later on in life...it will help them so much in life."

When I asked her suggestion to parents, Mary says that: "I think it's alright to kind of force, you know, maybe L1 in the home. I don't think anything wrong with that. I kind of wish my parents have done that.."

Second suggestion is making heritage language learning fun, and hiring someone to teach English to their children. Ally suggests to parents that:

"It is easier to find, you know, interactive games that you speak different languages, so, you know, kids will still be doing the things they wanna do or you know playing the video games, but maybe incorporate their home language into it, and just kind of you know, support the learning of that language with that.. keep speaking your language, but trying get help to teach their child English for their tests and things from someone like you know another teacher, someone who could help them."

Her suggestions are very important because she is aware that language learning should be fun for kids especially after they start school, and parents should not force themselves to teach English if they do not know English very well, and if they do not feel comfortable with it. Finding someone to do it can be an easy and practical way.

\section{2) To teachers}

All participants emphasized the significant role of teachers on their decisions to maintain their first language. Unfortunately, teachers usually had negative impacts in Kelly's and Mary's lives. Since Ally was in a bilingual school, she was mostly pleased with her teachers' attitudes towards her heritage language. Kelly explains her feelings about her teacher's attitude in this way:

"I think, like, teachers are very important because they would think it was so cool that I was from Turkey, and they would ask me questions like maybe individually, but like I never got to explain my classmates... so I feel like because they were so unaware, they didn't even know."

Her feelings show that she was frustrated because she did not have a chance to talk about her background or home culture to her classmates. Kelly continues with a crucial advice to teachers:

"Whatever their background is like make sure the class if it's elementary school or middle school, if there are foreign kids in the class, I feel like teachers should ask that child or the student with their permission, tell us about you so the whole class can learn you know" 
Therefore, the teachers should invite minority children to the classroom discussions and ask them to talk about their culture and language. By this way, immigrant children will have the opportunity to share about their funds of knowledge with their classmates, and feel important in the classroom community.

Kelly also makes some specific suggestions to teachers by using her own experiences at school. She says that:

There was a huge project, and it was like heritage week, and we had to do different activities. One of them was doing a code of arms where you have, like, different things that represent you. So my code of arms was that I had in one corner a Turkish flag, and in one corner the American flag. And then, I have like sports teams or something from each country like my favorite sports, teams and others. And then, that was one day, another day we had food, we brought food from our country, and then even if people are not like directly from, let's say Ireland or Germany, the fact that they even have to research and get to learn about those countries outside of them was very important, and we got to present and show pictures of the countries, and so it was really good. That's I feel like the only point I really felt like important. It is ok to be Turkish, it is ok to speak the language, and so."

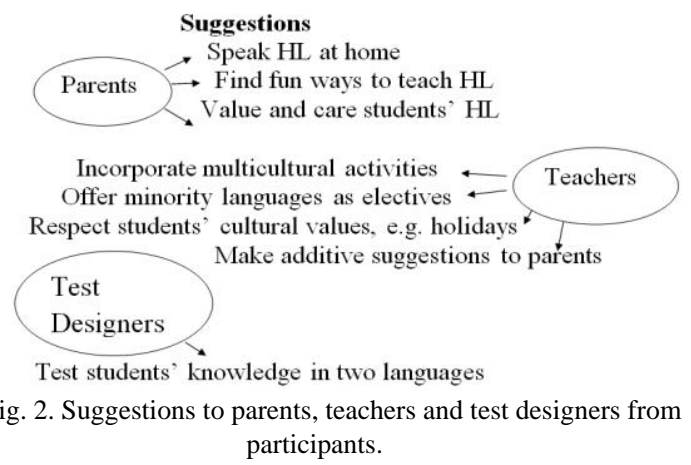

The project made her happy because she could reveal her identity through it, and her knowledge is valued by others. She recommends the teachers and schools to have similar projects that students can learn more about the other cultures.

Mary has some suggestions to involve minority languages in the school curriculum. She says that: ".. if there was at least an hour each day devoted to practicing or doing something playful or something in the first language (heritage language), I think that would be encouraging." She advises the school administrators to offer minority language classes at school at least for an hour so that minority students can maintain their first languages although it may be hard to do in practice.

Ally is not comfortable with the overlapping test dates and cultural holidays. She says

"They could value, I guess different things that come from the culture as well as not just the language. Where I am from it is a very Greek populated area but we don't get school offer epiphany, the one big holiday in Greek culture that we celebrate, so we would have tests something on those days, and that wasn't always showing the appreciation to having that other culture."

She also adds that:

"..teachers maybe at first, .., you know Greek was my primary language for example, maybe they allow me to write things Greek at first, and to slowly adjust and acknowledge that you know that still a part of my identity."

This shows that she had literacy in her first language when she started school, and she wanted to use it to support her second language learning.

Lastly, all participants think that teachers should encourage parents to speak their heritage languages at home. They think that when parents are confused about which language they should use at home with their English learning children, teachers should suggest them to use only heritage language or both so that the children can keep using the heritage language and not forget it.

3) To test designers

Ally has also emphasized the impact of tests on immigrant children's lives. She says that:

"I do remember when I was taking a gifted test in fourth grade, I could remember, they would show me different pictures and I had to name the object and I remember being able to think of the objects' name in Greek but not in English, and so that always ... Even to this day, something pop into my brain in Greek instead of English just because, you know what I associate with them to Greek words. So it feels tough sometimes, you know, having to split your brain between two different languages, it's sometimes difficult, but it's also helpful. But it's something that, you know, isn't taken into consideration as much by like people who give tests or make tests or something. They assume that you know certain, you know, slang words or phrases that I might know in Greek, but not necessarily in English, so that's the life of us, I guess."

Her quote suggests that the tests to place immigrant students into different classes may not be appropriate to measure their language competence. The test makers may not know the fact that two languages are combined in the bilinguals' brains, and bilingual children's vocabulary knowledge should be measured in both languages to reveal the exact size of vocabulary knowledge [4].

\section{CONCLUSION}

In conclusion, language shift can be an inevitable result for immigrants living in the USA. Schools, teachers and parents can have subtractive or additive influence on immigrant children's linguistic decisions. Prohibition of heritage languages in classes, disregarding immigrant children's heritage background, offering limited resources can be considered some subtractive roles of schools that result in language shift. Parents' subtractive ideologies can include allowing English at home or forcing children to speak only English at home so that the children can succeed at school. On the other hand, incorporating activities that value immigrant children's language and culture, and speaking only the heritage language at home usually result in maintenance of heritage language. Identity, family interactions, bilingualism, social pressures and stereotypes can be regarded the other motivational factors that encourage immigrant people to relearn their heritage language. Based on their experiences, the participants made some suggestions 
to teachers, parents and policy makers. Using both $L_{1}$ and $L_{2}$ at home, including bilinguals' cultures into classroom activities, teachers' additive suggestions to parents, respecting minority children's values and designing tests in both languages can be considered some suggestions to parents, teachers and test makers.

\section{IMPLICATIONS}

The teachers play a big role in immigrant children's linguistic decisions. Based on the participants' experiences, teachers' roles are usually subtractive. Therefore, they may want to be very careful in choosing their practices in the classrooms. They should keep in mind that their ideologies are absorbed by their students. They can involve immigrant children into the discussions and show them they respect and value their cultures. They can allow them to use their first language to some extent, and support their second language learning with their first language. They may choose activities that are appropriate to culturally diverse students in the class. They can teach them 'it is OK to be different from dominant culture'. They can build a classroom community that all members make equal contributions and respect each other.

\section{WhAT Is NEXT?}

This study is conducted with limited number of participants. The number of participants can be expanded for future works so that the results can be more generalizable. I have only one participant who had been in a bilingual program, and one participant who never learned her heritage language at home. To reveal different perspectives, after adding more participants to these groups, a comparison of these groups' experiences will show the different practices at different schools, and their long term effects on immigrant children's linguistic decisions. Lastly, I included only participants who rejected and (re)learned their heritage languages after language shift occurred. Studying people who never wanted to learn their heritage languages after language shift occurred may reveal other subtractive factors that are not discussed in this paper.

\section{ACKNOWLEDGMENT}

T. Yilmaz thanks to Prof. Ester de Jong and Assoc. Prof. Jane Townsend for their valuable contributions and feedback to this paper.

\section{REFERENCES}

[1] J. A. Fishman, Developing Minority Language Resources: The Case of Spanish in California, Clevedon, England: Multilingual Matters, pp. $12-23,2006$, ch. 4.

[2] L. Tse, Why Don't They Learn English?: Separating Fact from Fallacy in the U.S. Language Debate, United States of America: Teachers College Press, 2001.

[3] R. T. Anderson, Bilingual Language Development and Disorders in Spanish-English Speakers, Baltimore, MD, US: Paul H Brookes Publishing, 2004, pp. 187-211

[4] A. M. Padilla, "English only vs. bilingual education: Ensuring a language-competent society," Journal of Education. vol. 173, no. 2, pp. 1-38, 1991.
[5] Y. Wang, "Language, parents' involvement, and social justice: The fight for maintaining minority home language," Multicultural Education, vol. 16, no. 4, pp.13-18, Summer 2009.

[6] Z. Donghui, "Language maintenance and language shift among Chinese immigrant parents and their second-generation children in the U.S," Bilingual Research Journal, vol. 33, no.1, pp. 42-60, April 2010

[7] L. W. Fillmore, "When learning a second language means losing the first," Early Childhood Research Quarterly, vol. 6, pp. 323-346, 1991.

[8] E. Kutz, Language and Literacy: Studying Discourse in Communities and Classrooms, Heinemann: Portsmouth, NH, 1997.

[9] J. Leeman, R. Lisa, and E. Román-Mendoza, "Identity and activism in heritage language education," Modern Language Journal, vol. 95, no. 4, pp. 481-495, Winter 2011.

[10] J. W. Lindfors, Children's Language: Connecting Reading, Writing, Teachers College Press, 2008, ch. 1-2.

[11] M. Donaldson, Children's Minds, London: Fontana, 1978, ch. 3.

[12] M. A. K. Halliday, Language as Social Semiotic: The Social Interpretation of Language and Meaning, London: Edward Arnold, 1978.

[13] S. B. Heath, Ways with Words: Language, Life, and Work in Communities and Classrooms, United States of America: Cambridge Univ. Press, 1983, ch. 2-3.

[14] A. Tahriri, "Revisiting first language acquisition through empirical and rational perspectives," International Journal of Social Sciences and Education, vol. 3, no. 3, pp. 677-682, Jan. 2013.

[15] M. Chiu, L. P. Suet, M. Izumi, and C. Bonnie, "Immigrant students' emotional and cognitive engagement at school: A multilevel analysis of students in 41 countries," Journal of Youth and Adolescence, vol. 41 no.11, pp. 1409-1425, Nov. 2012.

[16] M. M. Bakhtin, Speech Genres and Other Late Essays, Texas, USA: University of Texas Press, 1986, ch. 2.

[17] D. Biber, C. Susan, and C. Viviana, Corpus Linguistics by the Lune: A Festschrift for Geoffrey Leech, Frankfurt: Peter Lang Publishing, 2003, pp. 71-92.

[18] L. Karanja, "ESL learning experiences of immigrant students in high schools in a small city," TESL Canada Journal, vol. 25, no. 2, pp. 23-41, Spring 2007.

[19] X. Liang, "Identity and language functions: High school Chinese immigrant students' code-switching dilemmas in ESL classes," Journal of Language, Identity and Education, vol. 5, no. 2, pp. 143-167, 2006.

[20] L. S. Vygotsky, Thought and Language, MIT Press, 1986.

[21] J. S. Townsend, and F. Danling, "A Chinese boy's joyful initiation into American literacy," Language Arts, vol. 75, no. 3, pp. 193-201, March 1998.

[22] J. S. Lee and E Oxelson, "'It's not my job': K-12 teacher attitudes toward students' heritage language maintenance," Bilingual Research Journal, vol. 30, no. 2, pp. 453-477, July 2006.

[23] J. Cummins, "Rethinking monolingual instructional strategies in multilingual classrooms," Canadian Journal of Applied Linguistics, vol. 10, no. 2 pp. 221-240, 2007.

[24] T. E. Larsen, "Preserving immigrant languages: Parent perspectives on the benefits of three heritage language schools," M.S. Thesis, Hamline University, St Paul, MN, 2011.

[25] B. E. H. Truyo, "Narratives of identity, nation, and outsiders within outsiders: Not yet a post-anything world," Harvard Latino Law Review, vol. 14, pp. 325-336, Spring 2011.

[26] V. G. Paley, The Girl with the Brown Crayon, Harvard Univ. Press, 1997.

[27] P. Farruggio, "Latino immigrant parents' views of bilingual education as a vehicle for heritage preservation," Journal of Latinos and Education, vol. 9, no. 1, pp. 3-21, Jan-March 2010.

[28] M. García, "Recent research on language maintenance," Annual Review of Applied Linguistics, vol. 23, pp. 22-43, 2003.

[29] P. DeGregory, Immigrants and their Children: Second Generation American Split between Cultures, 2010

[30] W. E. Lambert and M. T. Donald, "Assimilation versus multiculturalism: The view of urban Americans," Sociological Forum, vol. 3, no. 1, pp. 72-88, Winter 1988 .

[31] K. Nelson and J. M. Gruendel, "At morning it's lunchtime: A scriptal view of children's dialogue," Child Language: A Reader, New York, NY: Oxford University Press, 1988, pp. 263-277.

[32] D. J. Becker, "Parents' attitudes toward their children's heritage language maintenance: the case of Korean immigrant parents in West Michigan," Masters Theses, Grand Valley State Univ., Allendale, MI, 2013.

[33] J. Bruner, Acts of Meaning, Cambridge, MA: Harvard University Press, 1990 . 
[34] S. Jansen, "Language maintenance and language loss in marginalized communities: The case of the Bateyes in the Dominican Republic," International Journal of the Sociology of Language, vol. 221, pp. 77-100, 2013.

[35] Y. Wang, "Language, parents' involvement, and social justice: The fight for maintaining minority home language," Multicultural Education, vol. 16, no. 4, pp.13-18, Summer 2009.

[36] A. Winsler, R. M. Diaz, L. Espinosa, and J. L. Rodriguez, "When learning a second language does not mean losing the first: Bilingual language development in low-income, Spanish-speaking children attending bilingual preschool," Child Development, vol. 70, no. 2, pp. 349-362, Mar-Apr. 1999.

[37] Z. Donghui, "Language maintenance and language shift among Chinese immigrant parents and their second-generation children in the U.S," Bilingual Research Journal, vol. 33, no. 1, pp. 42-60, April 2010.

[38] S. M. Park and S. Mela, "Parents' attitudes toward heritage language maintenance for their children and their efforts to help their children maintain the heritage language: A case study of Korean-Canadian immigrants," Language, Culture and Curriculum, vol. 20, no. 3, pp. 223-235, Oct. 2007
[39] S. Yan and N. Elena, "Finding le mot juste: Differences between bilingual and monolingual children's lexical access in comprehension and production," Bilingualism: Language and Cognition, vol. 12, no. 3, pp. 323-335, July 2009.

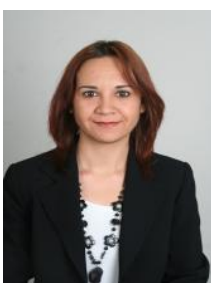

Tuba Yilmaz was born in Fethiye, Turkey on June 16, 1987. She studied English language teaching as an undergraduate student in Middle East Technical University. She completed her master's degree in the program of ESOL/bilingual education at the University of Florida. Currently she is doing her $\mathrm{PhD}$ degree in the program of ESOL/Bilingual education at the University of Florida

She worked as an English teacher at a primary school in Turkey for one year. Next, she worked as an instructor/lecturer in Selcuk University for two years. She presented a paper on classroom management at the ISSS conference in Orlando in February, 2014. 